\title{
O VERDADEIRO DA VERDADE EM FERNANDO PESSOA E CLARICE LISPECTOR OU UM PARALELO ENTRE O HETERÔNIMO E O ANÔNIMO ${ }^{(*)}$
}

\section{Daisy Justus ${ }^{(* *)}$}

"Há muito - não sei se há dias, se há meses - não registro impressão nenhuma; não penso, portanto não existo. Estou esquecido de quem sou; não sei escrever porque não sei ser. Por um adormecimento oblíquo, tenho sido outro. Saber que não me lembro édespertar." Fernando Pessoa - Livro do desassossego ${ }^{1}$

"Transfiguro a realidade e então outra realidade sonhadora e sonâmbula, me cria. E eu inteira rolo e à medida que rolo no chão vou me acrescentando em folhas, eu, obra anônima de uma realidade anônima só justificável enquanto dura a minha vida. E depois? Depois tudo o que vivi será de um pobre supérfluo."

Clarice Lispector - Água viva ${ }^{2}$

A proposta deste breve ensaio é pontuar na obra de dois mestres da literatura de língua portuguesa, Fernando Pessoa e Clarice Lispector, em estilos absolutamente próprios, a busca da marca da radical diferença subjetiva que permanentemente se inscreve na escritura de ambos, marca que se faz distintiva do seu desejo e de sua singularidade.

Tanto Fernando Pessoa quanto Clarice Lispector são exemplos extremos de uma das características da moderna corrente

\footnotetext{
(") Texto apresentado no VI Encontro do Centro de Estudos Fernando Pessoa. Curitiba, maio/2002.

("*) Psicanalista, Mestre em Antropologia Social - UFRJ.

I PESSOA, Fernando. Livro do desassossego. São Paulo: Companhia das Letras, 2002.

2 LISPECTOR, Clarice Água viva. Rio de Janeiro: Francisco Alves, 1994.
} 
literária: a introversão ao lado da objetividade. Os dois escritores levam o leitor a defrontar-se com o insondável, com a impessoalidade, com a angústia de existir, ao lado do eterno jogo de presença e ausência, um constante dentro e fora.

Sabemos que cada leitor, em qualquer circunstância, constrói, no ato da leitura, uma experiência própria e única. Sendo assim, "a produção do sentido implica a apropriação do texto pelo leitor"; daí a impressão "de sua própria singularidade na experiência da leitura", assinala Joel Birman ${ }^{3}$.

Quando essa referida experiência de leitura assume a tonalidade e a sonoridade de uma provocação, o leitor, ao aceitá-la, poderá ser surpreendido pelo movimento de deslizamento de seu próprio desejo, por vezes estagnado por situações as mais diversas.

Absurdemos a vida, de leste a oeste.

Fernando Pessoa ${ }^{4}$

O leitor passa a adquirir um maior conhecimento de si mesmo, condição fora de alcance até então, já que o texto irá transformá-lo em leitor-decifrador de sua própria subjetividade. O texto torna-se uma fonte de revelação para o próprio sujeito, já que ele é levado a rever gradativamente seus códigos de referência.

Há que se sublinhar neste ponto a presença daquilo que a Psicanálise chama de uma "experiência do inconsciente", resultado desse encontro singular que o texto provoca no leitor, a partir de uma determinada "experiência de leitura". Tanto Clarice quanto Pessoa capturam o leitor sem que esse se dê conta disso, impondo a revelação de uma lógica própria, capaz de avessar toda a sua coerência, desvelando múltiplas possibilidades de sentido.

O texto de Fernando Pessoa assim como o de Clarice Lispector são da ordem de uma mensagem cifrada, cabendo uma interpretação, uma tradução. Como no sonho. Ambos trazem à tona a problemática da crise da própria identidade, ou seja, o enfrentamento de um "quem eu sou?".

3 BIRMAN, Joel. Por uma estilística da existência. São Paulo: Editora 34, 1996.

4 PESSOA, Fernando. op.cit. 
Num ritmo de busca incessante colocam o leitor num clima de tensão que atravessa todo o texto, levando-o a encarar a fluidez de seu desejo e de sua própria existência. Sabemos que as palavras mudam as coisas: elas nos possibilitam desfazer nossos nós e restabelecer certas verdades, através do destronamento de fantasmas arcaicos. Somente por meio delas podemos identificar e vencer nossas resistências.

Vale lembrar que a importantíssima articulação entre o valor do texto literário e a subjetividade recebeu dois tratamentos enfáticos e determinantes. São eles: segundo Kafka, "para escrever é preciso morrer"; Maurice Blanchot dá mais um passo: "para morrer é necessário escrever" ${ }^{\prime \prime}$.

\section{Heteronomia $x$ anonimato}

Inúmeras são as tentativas de explicação para o fenômeno da heteronomia.

Umas simples, algumas mais complexas. Outras, menos ousadas, dizem apenas: é uma incógnita, trata-se de um enigma. O que parece difícil suportar é a cena do escritor à beira de seu abismo, ao mesmo tempo que ele, o leitor, é colocado simultaneamente à frente de seu próprio abismo, quando o escritor assina "Fernando Pessoa, ele mesmo", ou quando se apresenta "Fernando Pessoa, o outro", ou ainda nos faz deparar com a oposição à heteronomia: "Fernando Pessoa, ortônimo".

Conforme Nelson da Silva Junior ${ }^{6}$, Fernando Pessoa nos desenvolvido uma capacidade de "outrar-se", neologismo criado paralelamente ao processo da heteronomia. "Outrar-se significa um "tornar-se outro" de forma reflexiva. O outrar-se pode vir a ser a matriz dos diversos heterônimos, apontando para uma estrutura de alteridade", continua Silva Junior.

\footnotetext{
BLANCHOT, Maurice. O espaço literário. Rio de Janeiro: Rocco, 1987 SILVA JUNIOR, Nelson. Trauma e Fantasia - A ficcionalidade da Psicanálise. Hipótese a partir do Inquietante em Fernando Pessoa. In: BARTUCCI, Giovanna (org.). Psicanálise, literatura e estéticas da subjetivação. Rio de Janeiro: Imago, 2001
} 
"Fiz de mim o que não soube,

E o que podia fazer de mim não o fiz.

O dominó que vesti era errado.

Conheceram-me logo por quem não era e não desmenti, e perdi-me.

Quando quis tirar a máscara,

Estava pegada à cara.

Quando a tirei e me vi ao espelho,

Já tinha envelhecido

...E vou escrever esta história para provar que sou sublime. ${ }^{7}$

Pessoa propõe uma situação extremamente particular: ao explicitar a precariedade da estrutura emocional do humano, leva-nos à intimidade do silêncio, um silêncio seu, que ele o faz nosso. Traça um apagamento de si, ao mesmo tempo que nos arrasta a um apagamento próprio. Conserva-se no interior da obra, ultrapassando toda e qualquer possibilidade de apoio. Momento de travessia, ali onde o ele toma o lugar do eu. Ou será o contrário?

"Não sou ninguém, ninguém.

Sou o personagem de um romance ainda a ser escrito e flutuo, aéreo, disperso sem ter sido, entre os sonhos de um ser que não soube me acabar." ${ }^{8}$

Talvez esse venha a ser um dos caminhos através do qual Fernando Pessoa propicia a seus leitores tão estranha familiaridade com seu texto, com seus personagens. Leva-nos a ser cada um dos heterônimos, sendo também, com ele, Fernando Pessoa, ele mesmo. Íntimos da inquietude, íntimos do desassossego, da dúvida e da hesitação.

"Em cada uma dessas sensações sou outro, renovo-me dolorosamente em cada impressão, indefinida.

Vivo de impressões que não me pertencem, perdulário de renúncias, outro no modo como sou eu."

Poderíamos falar de condições para sustentar a heteronomia? De uma disciplina necessária para fazer seus os personagens de sua arte? Vivência dolorosa, só possível àqueles que têm muita intimidade

\footnotetext{
PESSOA, Fernando. op.cit.

PESSOA, Fernando. op.cit.

PESSOA, Fernando. op.cit.
} 
com a arte, onde talento e criatividade, ainda que indispensáveis, não são suficientes. A palavra, ao sustentar única e simplesmente seu valor de palavra, é que vai dar corpo ao personagem, oferecendo uma proliferação de sentidos, de nomes, de imagens que através de diferentes luzes e espelhos refletem um só nome: Fernando Pessoa. Nada mais que a palavra.

"Fernando Pessoa não existe, propriamente falando." Álvaro de Campos ${ }^{10}$

Mas enquanto no escritor Fernando Pessoa o enfrentamento da identidade se faz pela via da multiplicidade, a escritora Clarice Lispector nega sua identidade ao constituir-se em "carta anônima". A narradora de Água Viva considera-se como uma "obra anônima de uma realidade anônima".

"O verdadeiro pensamento parece sem autor". ${ }^{11}$

Clarice busca traduzir o monólogo interior, mergulhando numa linguagem nova para alcançar a sustentação de uma permanente indagação numa atmosfera densa e lúcida.

"Escrevo porque eu toda inteira sempre fui uma indagação sem resposta (...)"

"(...)escrevo por causa de uma solidão que independe dos outros. E também por sentir a necessidade de aprofundar as coisas, de vê-las como são por dentro". ${ }^{12}$

$\mathrm{Na}$ escrita de Clarice o enredo tem uma importância secundária: a ênfase é dada aos pequenos detalhes do cotidiano, quando sua narrativa permite uma fusão da sensibilidade da escritora com a de seu leitor. Lança mão de uma forte conotação de fantástico e de simbólico. Explora o metafórico. Clarice deixa claro que se sua subjetividade é inominável, o anonimato é seu modo único de existir:

"Eu me ultrapasso, abdicando de mim e então sou o mundo: sigo a voz do mundo, eu mesma de súbito com voz única." ${ }^{13}$

\footnotetext{
10 CAMPOS, Álvaro. Prefácio para uma Antologia de Poetas Sensacionistas.

11 LISPECTOR, Clarice. op. cit.

12 LISPECTOR, Clarice. op.cit.

13 LISPECTOR, Clarice. op. cit.
} 
Clarice tinha um hobby: a pintura. Dizia que pintava o "figurativo do inominável". A narradora sem nome de Água Viva também é pintora e busca, através da arte, sua imagem especular. O espelho é referido como objeto de reflexo da dor e do campo de silêncios. Silêncios que se desdobram em tantos outros. Sem nome. Ninguém. Anônima sempre.

"Na hora de pintar ou escrever sou anônima. Meu profundo anonimato que nunca ninguém tocou". ${ }^{14}$

Clarice abordou questões relativas principalmente ao universo feminino, ao cotidiano e à própria linguagem, numa sintaxe extremamente peculiar, pessoal. Na sua busca da origem, da essência, explorou com rigor e muita riqueza a estrutura da própria palavra em si, que, como várias de suas personagens, também é colocada diante do espelho. Aceitando-se naturalmente como dupla, utiliza a língua para refletir sua identidade e a diferença, o sim e o não.

"Eu sou sim. Eu sou não. Aguardo com paciência a harmonia dos contrários. Serei um eu, o que significa também vós." ${ }^{15}$

\section{À guisa de conclusão}

Podemos dizer que ambos, tanto Fernando Pessoa quanto Clarice Lispector, ao abrirem caminhos por lugares diferentes dos esperados, pretendem o alcance de sua própria verdade. seguinte recorte:

No Seminário de número 9, A identificação ${ }^{16}$, Lacan fez o

"Está claro que é atrás do verdadeiro que se corre; disse-lhes já que é o verdadeiro da verdade que se procura."

Na afirmativa de Lacan destaca-se esta expressão ao mesmo tempo instigante e sedutora: o verdadeiro da verdade. Qual a garantia de uma verdade, a qual o sujeito só poderá tê-la de si próprio, já que cada um tem a sua verdade? O que torna essa verdade legítima, já que ela será o estofo da tão cobiçada identificação? Árduo percurso, privilégio de poucos. Citamos Garcia-Roza: "Tentar atingir esse ponto derradeiro, ponto absoluto onde a palavra volta-se sobre si mesma,

\footnotetext{
14 LISPECTOR, Clarice. op. cit.

15 LISPECTOR, Clarice. op. cit.

16 LACAN, Jacques. Seminário 9 - A identificação: inédito.
} 
corresponderia, segundo Foucault, a algo parecido com a experiência da loucura. Loucura da linguagem ou o silêncio da palavra." 17

Percorrendo esse breve caminho mapeado por rápidos recortes na obra de Fernando Pessoa e Clarice Lispector, recorrendo à articulação dos campos da Literatura com a Psicanálise, podemos deduzir que o sujeito só alcançará sua verdadeira verdade através da sustentação da plasticidade das identificações humanas, onde os diferentes olhares, os diferentes ângulos, os diferentes espelhos, recortam a força da diferença de cada um, da particularidade subjetiva que nos é implícita. Lugar que chega ao ato criador em sua essência, exaltando o seu lado desejado e ao mesmo tempo assustador, temido, já que envolve a criação de realidades singulares.

Dito de outro modo, é como se Clarice e Pessoa nos exibissem a todo momento a repetição da diferença, já que será sempre de uma outra coisa que se trata, na busca incessante da verdade de cada um, que se faz intrínseca no processo mesmo da vida. Os referidos autores proclamam a transcendência dos limites da própria subjetividade, o rompimento das amarras e das certezas subjetivas.

Ainda uma citação de Clarice Lispector em Água viva ${ }^{18}$ :

"Sinto que nos chegamos ao limiar de portas que estão abertas e por medo ou pelo que não sei, não atravessamos plenamente essas portas. Que, no entanto, tem nelas já gravado nosso nome. Cada pessoa tem uma porta com seu nome gravado e é só através dela que essa pessoa perdida pode entrar e se achar. O meu "normal" está aquém de mim. Fui além de mim e não posso voltar mais."

Fernando Pessoa reitera em Livro do desassossego ${ }^{19}$ :

"A vida pode ser sentida como uma náusea no estômago, a existência da própria alma como um incômodo dos músculos. A desolação do espírito, quando agudamente sentida, faz marés, de longe, no corpo, e dói por delegação.

Estou consciente de mim em um dia, em que a dor de ser consciente é, como diz o poeta,

languidez, mareo

y angustioso afán."

17 GARCIA-ROZA, Luiz Alfredo. Introdução à metapsicologia freudiana. Rio de Janeiro: Jorge Zahar, 1993.

18 LISPECTOR, Clarice. op. cit.

19 PESSOA, Fernando. op.cit. 
Merleau Ponty ${ }^{20}$ em "A linguagem indireta $e$ as vozes do silêncio" faz uma observação que nos parece bastante propícia para interromper este estudo, que apenas abriu caminho para pessoais especulações futuras em torno dos dois escritores aqui destacados, Clarice Lispector e Fernando Pessoa: "O que há de risco na comunicação literária, e de ambíguo, irredutível à tese em todas as grandes obras de arte, não é um delíquio provisório do qual se pudesse esperar eximi-la, mas o esforço a que se tem de consentir para atingir a literatura, ou seja, a linguagem a explorar, que nos conduz a perspectivas inéditas em vez de nos confirmar as nossas."

\section{Referências Bibliográficas}

FORBES, Jorge. Fixões. In Agenda de psicanálise. Rio de Janeiro: Dumará.

GURGEL, Gabriela Lírio. A procura da palavra no escuro. Rio de Janeiro: 7 letras, 2001.

JORGE, Marco Antônio Coutinho. A iniciada sem seita. In Sexo e discurso em Freud e Lacan. Rio de Janeiro: Jorge Zahar, 1988.

KON, Noemi Moritz. Clarice Lispector: certas presenças permitem a transfiguração. Percurso - Revista de Psicanálise. Ano XI, n.21, 1998.

VARIN, Claire. Línguas de fogo - Ensaio sobre Clarice Lispector. São Paulo: Limiar, 2002.

\section{Daisy Justus}

Rua Major Rubens Vaz, 446 apt. 1301

Gávea - Rio de Janeiro - RJ

22470-070

tel.: (21) 2239-4932

e-mail: daisy.justus @ infolink.com.br

20 MERleau-PONTY, Maurice. A dúvida de Cézanne. São Paulo: Abril Cultural (Os Pensadores), 1980. 